\title{
MeCCSA-PGN 2015 Conference Special Issue Introduction
}

\author{
SIMON DAWES, Université Paul Valéry - Montpellier, France
}

In July 2015, the MeCCSA-PGN ${ }^{1}$ Annual Conference took place at Coventry University. Organised by Francien Broekhuizen, Danai Mikelli and Poppy Wilde, it was based around the theme of 'Transformative Practice and Theory: Where We Stand Today'. Over the two days of the conference, there were more than 30 presentations from postgraduate and early career researchers, as well as several workshops and keynote lectures from well-established figures in the field of Media, Communication and Cultural Studies. This issue of Networking Knowledge - the Journal of the MeCCSA-PGN, presents some of the highlights of the conference. Edited by the conference organisers and the journal editor, Simon Dawes, the articles selected here were submitted in the months following the conference and rigorously peer-reviewed and revised before being accepted for publication. The editors received a high number of articles from the conference participants, and all submissions received extensive feedback from the editors and anonymous peer-reviewers. Unfortunately, not all submissions were accepted, but the editors wish all those who submitted well with their future research and careers, and we look forward to reading their work with interest.

As well as eight full-length, peer-reviewed articles, this issue also features interviews with four of the keynote speakers: Clare Birchall, Lisa Blackman, Rebecca Coleman and Gary Hall. The issue editors conducted the interviews in the autumn of 2015, engaging with the talks given at the conference as well as the speakers' work as a whole. The issue then concludes with the conference organisers' behind-the-scenes report on the organisation and the running of the conference.

The issue begins with Alberto Micali's article, 'How to Become War Machine, Or... A Low Hacktivist (Un)Methodology in Pieces'. Inspired by McKenzie Wark's 'low theory' and Guattarian 'ecosophy', Micali (from the University of Lincoln) offers a theoretical and practical exercise in assemblage. Arguing that 'hacktivism' (hacking activism), understood as a set of disruptive media practices and actions, demands the elaboration of new methodological strategies, he outlines the theoretical and methodological rationale for his own 'low hacktivist methodology' as a necessarily temporary and fragmented approach. He concludes his article with an ontological discussion of 'machinism', in order to epistemologically strengthen his proposed method and interpret it as a post-human attempt of becoming with, rather than framing, 'hacktivist war-machines'.

Also from the University of Lincoln and dealing with some of the same theoretical concerns, Niall Flynn's article, 'Performativity and Metaphor in New Materialist Media Theory', takes as its starting point the shift in interest among some media theorists towards the process of mediation rather than stable media objects, and to rethink the materiality of media. Flynn

\footnotetext{
${ }^{1}$ Media, Communication and Cultural Studies Association - Postgraduate Network
} 
contends that such an embrace of materiality need not necessitate a refusal of representation. Indeed, in order to contribute to the ongoing reconceptualisation of materiality, and focusing on the performativity of method among new materialist scholars, he argues that metaphor can also be conceived as a constitutive and material process of mediation. The article then illustrates this by examining the trend in media studies that claims cinema itself as a type of theory. Flynn argues that this 'film-as-theory' discourse, despite appealing to performativity, separates theory and the film text in a way that presupposes an instrumental understanding of metaphor.

Eva Zekany, from the Central European University, continues this interest in media theory and materiality with her article, 'Through the Google Glass: Configurations of Attention in the Age of Digital Media'. After discussing the case of the first person ever to be treated for internet addiction induced by the use of Google Glass, Zekany draws on new materialism and the work of N. Katherine Hayles to interpret the case in terms of a reconfiguration of attention as an embodied, embedded and finite resource. She ultimately argues that Google Glass thus occupies a precarious and paradoxical place in today's attention economy.

In her article, 'Photography and the Visual Particularities of Young People on the Autism Spectrum', Uschi Klein (from the University of Brighton) draws on findings from an empirical study on the photographic practices of young people on the autism spectrum to discuss how participants use photography to capture the ways they see the world. Addressing the ways in which photography mediates autistic individuals' sensory perceptions of their visual world, and drawing on a phenomenological approach, Klein argues that autistic individuals appear to embody visuality with their sensory modalities, using primarily their vision, but also their kinaesthetic experience and proprioceptive awareness to photograph the world around them. Her article demonstrates how phenomenology provides a productive way of thinking about and understanding participants' photography as a way of being-in-theworld.

In 'Building a Digital Park: Recontextualising Lived Experiences at Towneley Park, Burnley', Alex McDonagh (University of Salford) discusses the effect of digital heritage on space and time. Discussing a particular research project that adopts a multidisciplinary and practicebased approach, engaging directly with local park users through interviews, field visits and the development of a website, McDonagh demonstrates how the project represents the rhizomatic and habitus-like qualities of human relationships with park spaces.

In her article, 'The Narrative Economy of Social Media: Mobilising Farming Economies, Identities and Relations', Adele Millard, from the University of Western Australia, focuses on the role of social media as a field of narrative exchange between producers and consumers. Detailing how Western Australian farmers of black truffles negotiate global consumer markets, Millard draws on the analytical concept of narrative economy to assess the farmers' use of social media, and critique the uneven distribution of symbolic and economic capital that their varied engagement with social media demonstrates.

In 'Negotiating Conflict: A Discussion of Interactive Documentary as Constructive Storytelling in Societies Emerging from Conflict', Jamie McRoberts (Queen's University Belfast) assesses the contribution of interactive documentary to the negotiation of complex and contested narratives of conflict. Exploring constructive storytelling and various modes of interactivity, he argues that future interactive documentary projects on war and conflict should 
creatively employ progressive technologies in order to enhance the range of constructive storytelling factors to maximise the possibilities for reconciliation.

Finally, Torgeir Fjeld (from the University of Gdansk in Poland) considers various notions of time in his article, 'Out of Time, or Anderson's National Temporality Revisited'. Engaging with Benedict Anderson's arguments about the shift from agrarian (cyclical) to national (linear) time with the rise of nation-states, and globalisation's undermining of this national temporality, Fjeld draws on the work of Walter Benjamin, Martin Heidegger, Jacques Lacan and others to offer a rich reflection on the concept of time. In doing so, he questions whether time itself is an a-temporal category, or whether it is our notion of time that has undergone change, as well as suggesting a third type of temporality missing from Anderson's narrative; a time bereft of both linearity and circularity.

Following these full-length articles, we include a series of interviews with the conference's keynote speakers. In the first interview on 'Openness and Opacity', Clare Birchall discusses the "sharing economy", "shareveillance" and the depoliticised subjectivity shaped by both open and opaque data. In order to re-imagine subjectivity in the face of shareveillance, Birchall calls on Édouard Glissant's "right to opacity". Ultimately, she explains how the concept of "sharing" can be politicised as a Commons, while the appropriation of opacity can become a political act. Her reassessment of the politics and values associated with openness and secrecy has implications for media scholars, particularly in terms of the need to think more critically about what kinds of publishing, networks and communications we want to develop.

In 'Haunted Data, Post-Publication Peer-Review and Body Studies', Lisa Blackman discusses her work on affect and the body, as well as her new book Haunted Data, which explores the creative and critical challenges of computational cultures for theories of affect and mediation, and the potential of PPPR (post-publication peer-review) to provide a corpus of data that be re-moved (Rheinberger) and performed for its hauntological potential. Working with the concept of 'haunted data' to follow those traces, deferrals, absences, gaps and their movements within a particular corpus of data, and to re-move and keep alive what becomes submerged or hidden by particular regimes of visibility and remembering, Blackman illustrates how these movements are simultaneously technical, affective, historical, social, political and ethical.

In 'Transformative Images, Temporality and Infra-structures of Feeling', Rebecca Coleman discusses the affective relations between bodies, images and environments. Coleman offers an overview of her work on images and the body, as well as her interest in theorising the present and the future, and explains her engagement with feminism, new materialism and Deleuze, in particular. To understand how bodies 'become', she argues for the need to understand both process, transformation and change, and what stays, sticks or gets stopped.

And in the final interview, 'Just Because You Write about Posthumanism Doesn't Mean You Aren't a Liberal Humanist', Gary Hall discusses the process of neoliberal subjectivation and the metricisation of the academy. Arguing that the focus of critique tends to be on the new, self-governing and self-exploitative subjects academics and students are transitioning into rather than scholarly subjectivity they are changing from, Hall argues that both the both the new neoliberal model (associated with the sharing economy) and the earlier liberal humanist model (associated with print-on-paper publishing) are involved in the subordination of scholarly agency and consciousness to the pre-programmed, controllable patterns of the 
capitalist culture industries. Discussing the various open access initiatives with which he's involved, he explains his attempts to not only critique and understand neoliberalisation, but to offer viable alternatives as well.

We close the issue with the organisers' report on the organisation and the running of the conference. In their visual essay, Francien Broekhuizen, Danai Mikelli and Poppy Wilde reflect on the process of hosting the conference, from submitting their initial bid, soliciting keynote speakers and making decisions on abstract submissions, to the running of the event itself and the ambitious incorporation of a wide range of social media to various aspects of the conference experience, from a dedicated website, YouTube channel, Google+ page, Facebook event and Twitter feed to the use of an interactive scheduling platform and Storify creations.

This issue represents the culmination of that process, and hopefully offers an accurate snapshot of the conference. On behalf of all the issue editors, I'd like to thank all those who submitted articles for consideration or who gave their time for interviews, as well as the many anonymous peer-reviewers who made this special issue possible. The next MeCCSA-PGN Conference will take place in July 2016 at the University of Leicester, with the theme of 'New Directions in Media Research', after which work will begin on the writing, reviewing, revising and editing of the best conference papers for another special issue of this journal. In the meantime, we hope that whether this issue brings back nostalgic memories of July 2015 in Coventry, or whets your appetite for July 2016 in Leicester, you enjoy reading the following articles and interviews.

Simon Dawes is interested in all aspects of media theory, history and regulation. He is currently writing a book, Broadcasting and the Public-Private Dichotomy (forthcoming, Palgrave Macmillan). He teaches at Université Paul Valéry, Montpellier (France), and works as Editorial Projects \& Website Manager for the journals Theory, Culture \& Society and Body \& Society. He is currently the Editor of Networking Knowledge - Journal of the MeCCSA$P G N$.

Email: simondawes0@gmail.com 